\title{
Antibody deficiency associated with gold treatment: natural history and management in 22 patients
}

\author{
N Snowden, D M Dietch, L S Teh, R C Hilton, M R Haeney
}

\begin{abstract}
Objective-To perform a clinical and immunological study of patients with rheumatoid arthritis who develop subnormal serum immunoglobulins on gold treatment; to clarify the nature of the defect in antibody production and determine the natural history of this adverse reaction; to use this information to suggest guidelines for the detection, investigation, and management of this complication.
\end{abstract}

Methods-22 patients who developed subnormal levels of one or more immunoglobulin isotypes while receiving gold treatment were recruited over a 10 year period from the practice of a single rheumatologist. Antibody production was assessed by measurement of total immunoglobulins and of specific antibody production against polysaccharide and protein antigens, with test immunisation if necessary.

Results-Two broad patterns of antibody deficiency were identified: $(1)(n=11)$ mild, affecting only one immunoglobulin isotype and with normal specific antibody production. These patients were in general able to continue gold without further deterioration in antibody production. (2) $(n=11)$ severe, affecting two or three immunoglobulin isotypes, with defective specific antibody production. Six patients developed significant infections and were treated with immunoglobulin. Gold was discontinued in all. Normal antibody production recovered in nine patients, and in all but one followed for more than one year. No relation was seen between duration/dose of gold and antibody deficiency.

Conclusions-Gold-induced antibody deficiency may be more common than usually recognised. A spectrum of deficiency exists, with some patients developing infective complications. Antibody production should be monitored in patients on gold treatment.

(Ann Rheum Dis 1996;55:616-621)

Moderate suppression of serum immunoglobulin levels occurs in approximately $50 \%$ of patients treated for rheumatoid arthritis with parenteral gold salts. ${ }^{1}$ Development of significant immunoglobulin deficiency is also recognised as a complication of gold treatment, and both selective IgA deficiency and severe panhypogammaglobulinaemia have been described. ${ }^{2-8}$ Pathological immunoglobulin deficiency is generally considered to be a very rare consequence of gold therapy, although little systematic information is available on the incidence and natural history of this adverse reaction. In 1987, two patients with severe gold induced hypogammaglobulinaemia were reported from this unit. ${ }^{8}$ Since that time, it has been our policy to measure serum immunoglobulins before starting gold treatment, after approximately six months of treatment, and annually thereafter (that is, after approximately every $1 \mathrm{~g}$ of gold given).

We report here a series of 22 patients who developed subnormal immunoglobulin levels on gold treatment, detected between 1985 and 1995. From our experience with these patients we suggest guidelines for the detection, investigation, and management of this complication and provide preliminary data on the prevalence and natural history.

\section{Methods}

STUDY POPULATION

Gold-induced immunoglobulin deficiency was defined as development of subnormal levels of one or more immunoglobulin isotypes in the course of gold treatment. Subnormal levels were defined as three standard deviations below the locally derived mean for a healthy adult population: $\operatorname{IgG}<6.5 \mathrm{~g}^{-1}$ litre $^{-1}, \operatorname{IgA}<0.6$ $\mathrm{g}$ litre ${ }^{-1}$, and IgM $<0.4 \mathrm{~g}_{\text {litre }}{ }^{-1}$. All subjects had normal immunoglobulin levels measured before starting gold or within six months of starting treatment, or (if pretreatment levels were unavailable) normal immunoglobulin concentrations after discontinuation of gold. Subjects with other causes for immunoglobulin deficiency were excluded (for example, loss from the kidneys or gut, B cell neoplasia). No patient had received treatment with azathioprine, cyclophosphamide, or any other cytotoxic drug. Clinical details were recorded on a standard proforma, including diagnosis, disease duration, previous treatment (and adverse reactions) with second line drugs, gold preparation used, duration of gold treatment, and total dose (to nearest $0.5 \mathrm{~g}$ ) given. Serial immunological data were recorded, in particular the lowest (nadir) immunoglobulin levels, and any changes in serum immunoglobulins on discontinuation of gold treatment. A record was made of any infectious episodes coinciding with the low immunoglobulin levels. 
LABORATORY METHODS

Immunoglobulins $G, A$, and $M$ were measured by rate nephelometry and IgG subclasses by radial immunodiffusion using WHO approved, subclass specific monoclonal antibodies. Assays of specific antibody production were also performed, assessing the adequacy of antibody production against common bacteria. ${ }^{10}$ In particular, measurements were made of antibodies against a representative bacterial polysaccharide antigen, the capsular polysaccharide of Streptococcus pneumoniae (in the form of Pneumovax II, a polysaccharide vaccine containing 23 pneumococcal serotypes), and a representative protein antigen, tetanus toxoid. In the early part of the study (1985-91) these antibody assays, together with other measurements of antimicrobial antibody production, were performed by reference laboratories (Department of Immunology, East Birmingham Hospital for pneumococcal antibodies; Public Health Laboratory Service for antitetanus antibody levels). Since 1991 these specific antibody assays have been performed in house by enzyme linked immunosorbent assay (ELISA) after the method of Kumararatne and colleagues. ${ }^{11}{ }^{12}$ Subjects found to have subprotective levels of antipneumococcal or antitetanus antibodies $(<1 / 320$ for antipneumococcal IgG or $<0.01 \mathrm{IU} \mathrm{m}^{-1}$ for tetanus toxoid) were subjected to immunisation with standard $0.5 \mathrm{ml}$ doses of Pneumovax or tetanus toxoid. Antibody concentrations were remeasured four weeks after immunisation. Those subjects who did not achieve at least a doubling in antibody titre or a rise into the protective range were considered to have significant defects in specific antibody production. Those subjects with baseline antibody titres within the protective range, or who responded adequately to immunisation, were considered to have normal specific antibody production. This definition of normal antibody production does not exclude subtle defects in antibody synthesis (for example, specific defects in response to particular pneumococcal serotypes), but does provide a useful working measure of the capacity to synthesise specific immunoglobulin.

$T$ and $B$ cell subsets were determined by flow cytometry, using standard methodology and monoclonal antibodies against $\mathrm{CD} 3$, CD4, CD8, CD19, CD20 and HLA DR. Reference ranges were as previously described. ${ }^{12}$

\section{Results}

Clinical and immunological features in the 22 patients with gold induced immunoglobulin deficiency are summarised in tables 1 and 2 .

The median age was 64 years (range 44-86); three subjects were male and 19 female. Twenty patients had rheumatoid arthritis (1987 ARA criteria) and two had a psoriatic polyarthritis. Median disease duration at the initiation of gold treatment was four years (range three months to 18 years). All patients received treatment with sodium aurothiomalate (Myocrisin) and all were considered to have responded successfully to gold treatment in terms of improvement in clinical or laboratory parameters of disease activity. Median duration of gold treatment before detection of decreased serum immunoglobulins was four years (range six months to 13 years) and the median total dose of gold given was $2.5 \mathrm{~g}$ (range 0.5 to $10 \mathrm{~g}$ ).

Two broad patterns of immunoglobulin deficiency could be identified: (1) those with a decrease in serum immunoglobulins restricted to a single isotype and relatively mild immunodeficiency, and (2) those with a decrease in two or three isotypes and a high incidence of significant defects in specific antibody production.

DECREASE IN SINGLE ISOTYPE (table 1)

In these 11 patients (median age 64, median total dose of gold $2.5 \mathrm{~g}$, median duration of gold treatment four years), the isotype affected was IgG in six, IgA in one, and IgM in four. Lowest immunoglobulin measurements within this group were: IgG $4.3 \mathrm{~g} \mathrm{litre}^{-1}$, IgA $0.1 \mathrm{~g}$ litre $^{-1}$, and IgM $0.26 \mathrm{~g}_{\text {litre }}{ }^{-1}$. Specific antibody studies were performed on seven of 11 patients and showed a defect in specific antibody production in two of the seven. One patient (case 1), with IgA deficiency, normal total IgG, but low IgG1 and IgG3 and a specific antibody defect, developed recurrent chest infections and was treated with intravenous immunoglobulin for six months, after which time the functional defect had recovered. No other patient had severe or recurrent infection. Seven patients continued gold treatment with no further decrease in immunoglobulins. Follow up at times ranging from six months and four years after the nadir immunoglobulin level showed that serum immunoglobulins had improved in $10 / 11$ patients, and only two patients still had a subnormal immunoglobulin concentration (case 2, IgG $6.1 \mathrm{~g} \mathrm{litre}^{-1}$; case 7, IgM $0.34 \mathrm{~g}$ litre $\left.^{-1}\right)$. Changes in immunoglobulin concentration over time in a representative patient from this group are shown in fig 1.

DECREASE IN MORE THAN ONE ISOTYPE (table 2) In these 11 patients (median age 63 years, median total dose of gold $2.5 \mathrm{~g}$, median duration of treatment four years), all isotypes were decreased in three, IgG and IgA in one, IgG and IgM in six, and IgA and IgM in one. Lowest levels were: IgG $2.7 \mathrm{~g}$ litre $^{-1}$, IgA $0.02 \mathrm{~g}$ litre $^{-1}$, and IgM $0.05 \mathrm{~g} \mathrm{litre}^{-1}$. Specific antibody

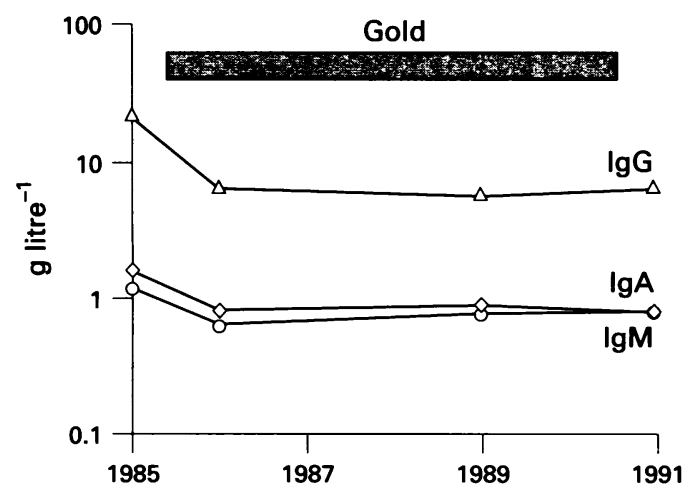

Figure 1 Serial immunoglobulin estimations over a six year period from patient 6 , showing duration of gold treatment. 
Table 1 Mild defect

\begin{tabular}{|c|c|c|c|c|c|c|c|c|c|c|}
\hline $\begin{array}{l}\text { Patient } \\
\text { No }\end{array}$ & Age/sex/diagnosis & Timeldose & $\begin{array}{l}\text { Pre-gold } \\
\text { Igs }\end{array}$ & $\begin{array}{l}\text { Nadir } \\
\text { Igs }\end{array}$ & IgG subs & Specific antibody & $T / B$ cells & Infection & Treatment/follow up & Outcome \\
\hline \multirow[t]{3}{*}{1} & \multirow[t]{3}{*}{$f / 61-R A$} & \multirow[t]{3}{*}{10 years $7 \mathrm{~g}$} & 7.5 & 6.9 & $\downarrow$ IgG1 & pn neg & Normal & $\begin{array}{l}\text { Recurrent chest } \\
\text { UTI }\end{array}$ & ivig $6 / 12$ & 7.5 \\
\hline & & & 1.2 & 0.1 & \multirow[t]{2}{*}{$\downarrow$ IgG3 } & \multirow[t]{2}{*}{ tt neg } & & & & 0.1 \\
\hline & & & 0.5 & 0.45 & & & & & 1 year & $\begin{array}{l}0.8 \\
\text { pn pos } \\
\text { tt pos }\end{array}$ \\
\hline \multirow[t]{3}{*}{2} & \multirow[t]{3}{*}{ f/61-RA } & \multirow[t]{3}{*}{2 years $2.5 \mathrm{~g}$} & 8.7 & 5.9 & \multirow{3}{*}{$\begin{array}{l}\downarrow \text { IgG1 } \\
\downarrow \text { IgG3 }\end{array}$} & \multirow{3}{*}{$\begin{array}{l}\text { pn neg } \\
\text { tt pos } \\
\star\end{array}$} & \multirow[t]{3}{*}{ ND } & \multirow[t]{3}{*}{ None } & Gold & 6.1 \\
\hline & & & 1.8 & 1.4 & & & & & Continued & 1.5 \\
\hline & & & 0.9 & 0.4 & & & & & 2 years & 0.7 \\
\hline \multirow[t]{3}{*}{3} & \multirow[t]{3}{*}{$\mathrm{f} / 58+\mathrm{RA}$} & \multirow{3}{*}{1.5 years $2 \mathrm{~g}$} & 7.5 & 5.8 & \multirow{3}{*}{$\begin{array}{l}\downarrow \text { IgG1 } \\
\downarrow \downarrow \text { IgG3 }\end{array}$} & \multirow{3}{*}{$\begin{array}{l}\text { pn neg } \\
\text { tt neg }\end{array}$} & \multirow[t]{3}{*}{ ND } & \multirow[t]{3}{*}{ None } & Gold & 7.5 \\
\hline & & & 1.6 & 1.1 & & & & & Stopped & 1.3 \\
\hline & & & 1.5 & 0.7 & & & & & 1 year & $\begin{array}{l}1.2 \\
t t\end{array}$ \\
\hline \multirow[t]{3}{*}{4} & \multirow[t]{3}{*}{$f / 66+R A$} & \multirow[t]{3}{*}{6 years $7 \mathrm{~g}$} & 8.0 & 5.6 & \multirow[t]{3}{*}{ ND } & pn pos & \multirow[t]{3}{*}{ ND } & \multirow[t]{3}{*}{ None } & Gold & 11.7 \\
\hline & & & 1.1 & 0.6 & & tt pos & & & Continued & 1.8 \\
\hline & & & 0.6 & 0.42 & & $\star$ & & & 7 years & 0.6 \\
\hline \multirow[t]{3}{*}{5} & $f / 62+R A$ & 6 months $1 \mathrm{~g}$ & 13.9 & 9.3 & $\downarrow$ IgG2 & ND & ND & None & Gold & 9.8 \\
\hline & & & 3.3 & 1.4 & & & & & Continued & 1.8 \\
\hline & & & 0.45 & 0.26 & & & & & 6 years & 0.4 \\
\hline 6 & $\mathbf{f} / \mathbf{8 4}+\mathbf{R A}$ & 6 years $5 \mathrm{~g}$ & 22.1 & 4.8 & $\downarrow \operatorname{IgG1}$ & ND & ND & None & Gold & 6.4 \\
\hline & & & 1.6 & 0.6 & $\downarrow$ IgG3 & & & & Stopped & 1.0 \\
\hline & & & 1.2 & 0.44 & & & & & 4 years & 0.8 \\
\hline 7 & f/76 PsA & 5 years $6 g$ & 13.7 & 9.2 & Normal & ND & ND & None & Gold & 10.7 \\
\hline & & & 3.9 & 1.8 & & & & & Continued & 2.2 \\
\hline & & & 0.9 & 0.25 & & & & & 5 years & 0.34 \\
\hline 8 & $\mathrm{f} / 64+\mathrm{RA}$ & 5 years $6 \mathrm{~g}$ & 7.2 & 5.9 & $\downarrow \operatorname{IgG1}$ & pn pos & ND & None & Gold & 6.8 \\
\hline & & & 0.9 & 1.0 & $\downarrow \mathrm{IgG3}$ & tt pos & & & Stopped & 0.9 \\
\hline & & & 0.9 & 0.90 & & $\star$ & & & 6 months & $\begin{array}{l}1.0 \\
\text { pn pos }\end{array}$ \\
\hline & & & & & & & & & & tt pos \\
\hline 9 & $\mathrm{~m} / 70+\mathrm{RA}$ & 4 years $2 \mathrm{~g}$ & 16.9 & 13.2 & ND & ND & ND & None & Gold & 14.7 \\
\hline & & & 4.0 & 2.9 & & & & & Continued & 2.7 \\
\hline & & & 0.41 & 0.34 & & & & & 4 years & 0.43 \\
\hline 10 & $f / 51+R A$ & 2 years $2.5 \mathrm{~g}$ & 8.9 & 7.8 & Normal & pn pos & ND & None & Gold & 9.1 \\
\hline & & & 2.1 & 0.2 & & & & & Continued & 0.7 \\
\hline & & & 2.3 & 2.1 & & & & & 2 years & 2.1 \\
\hline 11 & $\mathrm{f} / 67+\mathrm{RA}$ & 2.5 years $2.5 \mathrm{~g}$ & ND & 4.3 & $\downarrow$ IgG2 & pn pos & Normal & None & Gold & 7.1 \\
\hline & & & & 0.9 & & tt pos & & & Stopped & 1.3 \\
\hline & & & & 0.80 & & & & & 6 months & 0.72 \\
\hline
\end{tabular}

+ RA, seropositive RA; -RA, seronegative RA; PsA, psoriatic arthropathy; Igs, immunoglobulins; pn, anti-pneumococcal antibodies; tt, anti-tetanus toxoid antibodies; pos, specific antibody titre within protective range before or after test immunisation (those requiring test immunisation are marked with an asterisk ${ }^{\star}$ ); neg, specific antibody titre subprotective despite test immunisation; imig, intramuscular immunoglobulin treatment; ivig, intravenous immunoglobulin treatment; In Treatment and follow up column, the first two lines refer to the treatment given, the continuance or otherwise of gold treatment (all patients receiving immunoglobulin stopped gold), and the duration of this treatment. The third line in this column refers to the total duration of follow up from the nadir immunoglobulin level.

Immunoglobulin levels and specific antibody responses in the outcome column are those at the follow up duration given in the preceding column. All immunoglobulin leves are expressed in $\mathrm{g}$ litre ${ }^{-1}$; the top figure refers to IgG, the middle to IgA, and the third to IgM.

$\mathrm{ND}$, investigation not performed or data not available for study.

studies showed a significant defect in $10 / 11$ cases (significant in comparison with the specific antibody defect in those with a decrease in a single isotype, $P=0.013$, Fisher's exact test, odds ratio $25,95 \%$ confidence interval for odds ratio 2.2 to 253 ). Four patients suffered recurrent chest infections (including one who developed a deterioration in her long standing bronchiectasis) and one patient had an early wound infection following a total knee replacement. Ten patients discontinued gold treatment: six were treated with immunoglobulin replacement therapy for periods of between six months and two years, and four received prophylactic penicillin $\mathrm{V}$ in view of their inadequate capacity to produce pneumococcal antibodies. Two patients (cases 12 and 13) received intramuscular immunoglobulin for two years and 18 months respectively, at which time all immunoglobulin isotypes were noted to have risen significantly and replacement was discontinued. Since immunoglobulin replacement preparations, whether intramuscular or intravenous, contain almost exclusively IgG with almost no IgA or IgM, improvement in serum IgA and IgM concentrations in patients on replacement reflects increases in endogenous synthesis. Improvement in IgG production is harder to assess because of masking by the administered IgG. However, because of the limited dose of immunoglobulin which can be given by the intramuscular route, IgG concentrations in patients receiving intramuscular replacement rarely rise more than $2-3 \mathrm{~g} \mathrm{litre}^{-1}$ above baseline levels. A progressive rise above this increment occurred in cases 12 and 13. In patients receiving intravenous immunoglobulin, now almost exclusively used in preference to intramuscular preparations because of the ease with which sufficient IgG can be given to normalise IgG levels, improvements in IgG can only be ascertained reliably by stopping replacement treatment for at least three months and repeating serum immunoglobulin measurements. Three patients (cases 14, 15, and 16) received intravenous immunoglobulin for six months, at which time a significant increment was noted in IgA, IgM, or both. Immunoglobulin treatment was then discontinued and subsequent immunoglobulin estimation and test immunisation confirmed normal specific antibody production in all, although total immunoglobulin concentrations remained slightly subnormal in all three. In the patients who received penicillin $V$, immu- 
Table 2 Severe defect

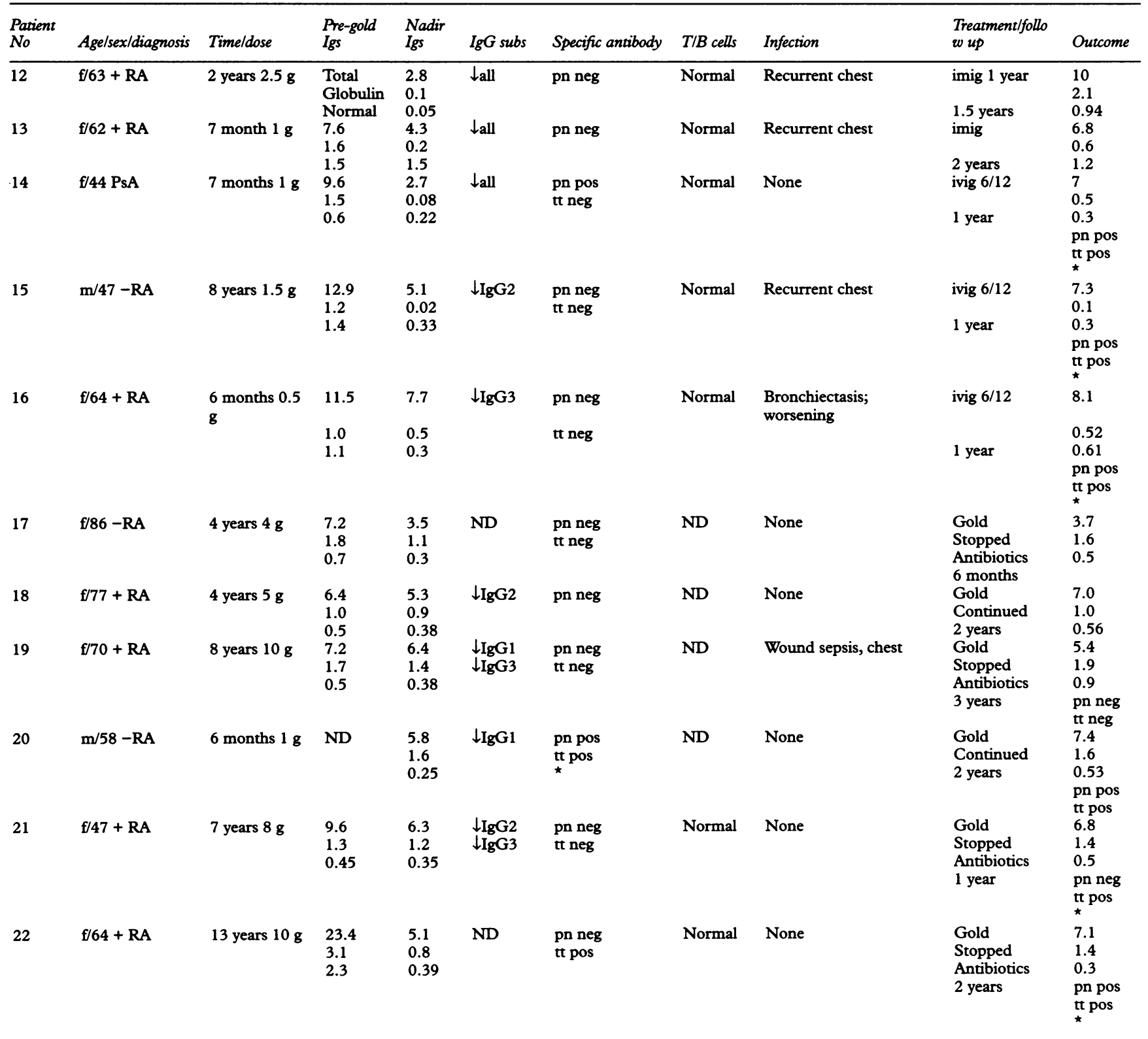

+ RA, seropositive RA; -RA, seronegative RA; PsA, psoriatic arthropathy; Igs, immunoglobulins; pn, anti-pneumococcal antibodies; tt, anti-tetanus toxoid + RA, seropositive RA; - RA, seronegative RA; PsA, psoriatic arthropathy; lgs, immunoglobulins; pn, anti-pneumococcal antibodies; $t$, marked with an asterisk ${ }^{\star}$ ); neg, specific antibody titre subprotective despite test immunisation; imig, intramuscular immunoglobulin treatment; ivig, intravenous immunoglobulin treatment; In neg, specific antibody titre subprotective despite test immunisation; imig, intramuscular immunoglobulin treatment; ivig, intravenous immunoglobulin Treatment and follow up column, the first two lines refer to the treatment given, the continuance or otherwise of gold treatment (all patients receiving
immunoglobulin stopped gold), and the duration of this treatment. The third line in this column refers to the total duration of follow up from the nadir immunoglobulin level.

Immunoglobulin levels and specific antibody responses in the outcome column are those at the follow up duration given in the preceding column.

All immunoglobulin leves are expressed in $\mathrm{glitr}^{-1}$; the top figure refers to IgG, the middle to IgA, and the third to IgM.

ND, investigation not performed or data not available for study.

noglobulin concentrations recovered in two and remained subnormal but static in two. One patient (case 20) with subnormal IgG and IgM but normal specific antibody production continued gold treatment, with normalisation of immunoglobulin concentrations after six months. Two of the patients receiving prophylactic antibiotics had persistent specific antibody defects at one year (case 21) and four years (case 19). Case 17 was lost to follow up after six months, at which time the immunoglobulins were still subnormal. Serial immunoglobulin levels from a representative patient from this group are shown in fig 2 .

IgG subclass measurements were performed in 19 patients. The commonest pattern of IgG subclass deficiency was combined reduction of IgG1 and IgG3, although partial IgG2 deficiency was seen in four patients. IgG subclass measurement contributed little extra information to that provided by total IgG measurements and specific antibody studies.

$T$ and $B$ cell numbers were normal in all patients studied.

\section{Discussion}

The series of patients presented here shows that a wide spectrum of antibody deficiency occurs as a result of gold treatment. Depression of immunoglobulin production is not confined to any single isotype or IgG subclass and affects responses to polysaccharides and proteins. Two broad patterns of deficiency emerge: one relatively mild and affecting only a single immunoglobulin isotype; the other more severe, with depression of more than one 


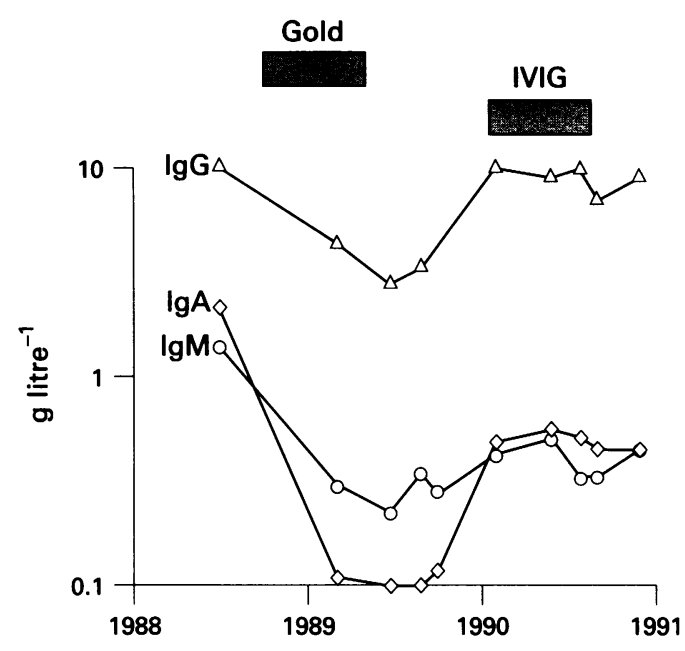

Figure 2 Serial immunoglobulin estimations over a 2 year period from patient 14, showing relation to gold treatment and immunoglobulin replacement (IVIG).

isotype and associated with severe defects in specific antibody production and recurrent infection. Depression of a single isotype should not be regarded as an entirely benign occurrence: two of the cases with this pattern of deficiency had defects in the production of protective antibacterial antibodies despite normal total concentrations of IgG, and were thus at risk of infection. This emphasises the central importance of specific antibody assays in the investigation of gold induced antibody deficiency and also reflects the wider use of these assays in clinical immunology in the assessment of immunodeficiency.

None of the product data sheets for any of the gold preparations available in the United Kingdom indicate that serum immunoglobulins should be monitored during treatment, ${ }^{14}$ and immunoglobulin measurement is not mentioned in recent guidelines on the monitoring of second line drug treatment published by the British Society for Rheumatology $^{15}$ This reflects the perception that gold induced antibody defects are extremely rare. Our finding of 22 cases in a single unit over a 10 year period suggests that this adverse reaction may be more common than generally believed. We do not have a precise count of the number of patients treated with gold but the total is around 1000 , suggesting that $2 \%$ or more of patients treated with gold develop antibody defects, a figure which we consider justifies a policy of screening immunoglobulin levels at least annually and in any patient presenting with recurrent or severe bacterial infection. Although some patients developed immunoglobulin deficiency in the early stages of gold treatment, the majority of the cases reported here had been on gold for two or more years, and two patients for more than 10 years, before the low immunoglobulins were detected. This suggests that monitoring of immunoglobulin levels is required throughout gold treatment.

The natural history of gold induced antibody deficiency has not previously been delineated. The cases reported here suggest that patients with mild defects and with normal specific antibody production can usually be maintained on gold treatment with no further decline in immunoglobulin production. Patients who discontinue gold treatment because of a severe defect in total antibody production will usually recover normal immunoglobulin concentrations and specific antibody production, although a proportion show no evidence of recovery one year or more following discontinuation of gold, and in one patient (case 19), a persistent specific antibody defect was still apparent after three years. No clear relation was seen between duration and dose of gold treatment and time for recovery of immunoglobulin production; recovery time did, however, seem to be slower in those subjects with severe antibody defects. Recovery times varied between two months (case 20) and two years (case 13).

Gold is known to produce moderate decrements in immunoglobulin in the majority of patients treated, ${ }^{1}$ suggesting that overt antibody deficiency may represent differential susceptibility to a pharmacological action of the drug rather than an idiosyncratic response to gold. One of the patients reported here (case 18) and previously ${ }^{8}$ had a partial deficiency of IgG3 predating treatment with gold, suggesting that minor defects in immunoglobulin synthesis might predispose to more severe defects while on gold treatment. No patient in our series had abnormal total immunoglobulins before treatment, but unfortunately no data are available on pretreatment IgG subclass or specific antibody activity for the remainder of the patients.

Defects in immunoglobulin production have been described with other second line drugs used in the treatment of rheumatoid arthritis. ${ }^{3}{ }^{16}$ It is our impression that antibody deficiency is very much more common following gold treatment than with other drugs. Over the time period of this study we have only been aware of immunoglobulin deficiency developing in two patients on penicillamine, in one on methotrexate, and in no patients on sulphasalazine. However, this impression may be distorted by the frequency of use of these drugs in our unit and the relative infrequency of immunoglobulin measurement in patients on drugs other than gold.

Our policy for screening, investigation, and management of gold induced antibody deficiency has evolved with our clinical experience. In fig 3 we outline a simple algorithm for the investigation of patients who develop decreased serum immunoglobulins on gold treatment. This is not intended to be a dogmatic schedule for investigation but rather as an aid to clinical management and as a starting point for future study. Our current strategy for management is to allow patients with no specific antibody defect to continue treatment with regular monitoring of specific antibody activity. In patients with a significant specific defect we discontinue gold and institute some form of prophylaxis against infection; with immunoglobulin replacement if infective complications have occurred (or seem likely to occur, as in the patient who had long standing severe bronchiectasis) or with 


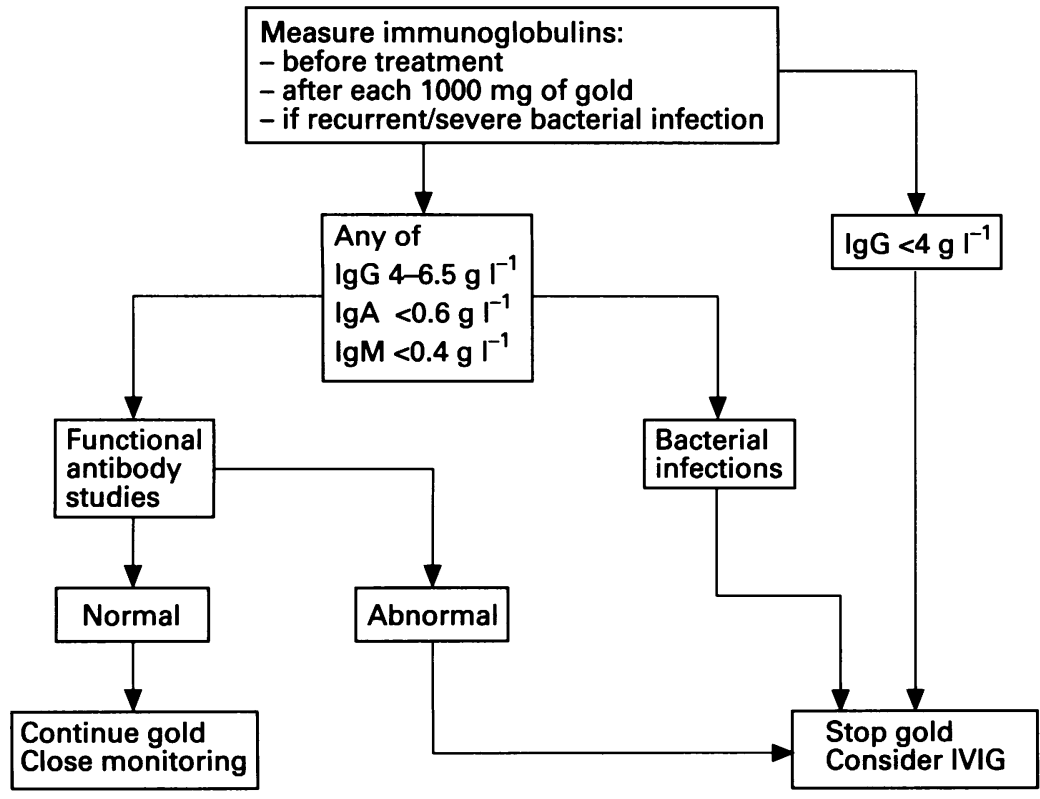

Figure 3 Algorithm for the suggested investigation and management of gold induced antibody deficiency. If infection occurs in a patient on gold and no defect is found in antibody production (and the neutrophil count is normal) then gold can be cautiously continued following completion of investigations.

prophylactic penicillin $\mathrm{V}$ if the patient is well. Immunoglobulin treatment is continued for six months initially and cautiously discontinued at the end of this period if the IgA or IgM have improved or if the IgG level is rising and higher than that predicted by the replacement dose of immunoglobulin. Antibody production is then reassessed after a period of three months off immunoglobulin treatment (half life of infused IgG is around 21 days). During this three month period, we maintain the patient on prophylactic antibiotics to minimise the risk of sepsis if antibody production does not recover. Treatment with immunoglobulin carries the theoretical risk of delaying recovery of intrinsic antibody production by negative feedback. However, since the great majority of our patients show recovery of IgA and IgM production while still on immunoglobulin replacement and recover IgG production rapidly after immunoglobulin is discontinued, the potential benefits of immunoglobulin replacement in patients at high risk of infection would seem to outweigh any theoretical risks. We have chosen to discontinue gold in all our patients with evidence of a severe functional defect in antibody production. Since IgG replacement therapy provides a high degree of protection against infection in patients with primary antibody deficiency ${ }^{17}$ it would perhaps be reasonable to continue gold treatment in parallel with intravenous immunoglobulin (or antibody prophylaxis) in patients whose arthritis is optimally controlled on gold and in whom no alternative treatment exists.

It could be argued that if gold-induced antibody defects do occur in $2 \%$ of patients treated with this drug then this would be clinically obvious and that we have overestimated the prevalence and significance of this adverse reaction. However, rheumatoid arthritis is a disease associated with high morbidity and mortality from infection. Death from infection is nine times more common in patients with rheumatoid arthritis than the general population; the majority of these excess deaths are due to pneumonia. ${ }^{18} 19$ This susceptibility to infection is poorly understood: corticosteroid or cytotoxic drugs may predispose to infection in some patients, and it has been suggested that an intrinsic immune defect may be part of the rheumatoid disease process. It may be that gold-induced antibody defects contribute to this susceptibility to infection. A recent study suggested that patients with rheumatoid arthritis who develop bronchiectasis have almost invariably received prior treatment with gold, although nothing is known of antibody production in these patients. ${ }^{20}$ We suggest that monitoring of immunoglobulin concentrations in patients on gold treatment has potential for reducing the burden of infection in rheumatoid arthritis, and that the effects of gold on specific antibody production require further evaluation.

1 Lorber A, Simon T, Leeb J, Peter A, Wilcox S. Chrysotherapy: suppression of immunoglobulin synthesis. Arthriti Rheum 1978;21:785-91

2 So AKL, Peskett SA, Webster ADB. Hypogammaglobulinaemia associated with gold therapy. Ann Rheum Dis 1984;43:581-2.

3 Lee AH, Levinson AI, Schumacher HR. Hypogammaglobulinaemia and rheumatic disease. Semin Arthritis Rheum 1993;22:252-64.

4 Guillemin F, Bene M-C, Aussdat R, Bannwarth B, Pourel J. Hypogammaglobulinaemia associated with gold therapy: evidence for a partial maturat

5 Stanworth DR, Johns P, Williamson N, Shadforth M, FelixDavies D, Thompson R. Drug-induced IgA deficiency in theumatoid arthritis. Lancet 1977; i:1001-2.

6 Hunter T. Hypogammaglobulinaemia associated with gold therapy. Ann Rheum Dis 1985;44:212.

7 Olsen JC, Lovell DJ, Levinson JE. Hypogammaglobulinaemia associated with gold therapy in a patient with juvenile rheumatoid arthritis. $\mathcal{F}$ Rheumatol 1986;13:224-5.

8 Burns HJ, Klimiuk PS, Hilton RC, Haeney M. Goldinduced hypogammaglobulinaemia. Br $\mathfrak{f}$ Rheumatol 1987; 26:53-5.

9 Jefferis $R$, Kumararatne DS. Selective IgG sub-class deficiency: quantification and clinical relevance. Clin Exp Immunol 1990;81:357-67.

10 Wheeler JG, Steiner D. Evaluation of humoral responsiveness in children. Pediatr Infect Dis f 1992;11:304-10.

11 Hazlewood $M$, Nusrat $R$, Kumararatne DS, Goodall $M$, Raykundalia C, Da Gong W, et al. The acquisition of antipneumococcal capsular polysaccharide, Haemophilus influpneumococcal capsular polysaccharide, Haemophilus influenzae type b and tetanus toxoid antibodies,
UK. Clin Exp Immunol 1993;93:157-64.

12 Kumararatne DS, Bignall A, Joyce HJ, Hazlewoof M. Antibody deficiency disorders. In: Chapel HM, Gooi HC, eds. Clinical immunology: a practical approach. London: IRI press, 1990:1-22.

13 Bansal AS, Moran A, Potter M, Taylor R, Haeney MR, Mandal BK. Lymphocyte transformation responses to PHA and PWM in pateints at different stages of HIV infection: are they worth measuring? $f$ Clin Pathol 1993;46:846-8.

14 ABPI data sheet compendium 1995-6. London: Datapharm, 1995.

15 British Society For Rheumatology. Guidelines for therapeutic drug monitoring. London: British Society for Rheumatology, 1995

16 Farr M, Kitas GD, Tunn EJ, Bacon PA. Immunodeficiencies associated with sulphasalazine therapy in rheumatoid arthritis. Br $\mathcal{F}$ Rheumatol 1991;30:413-7.

17 Chapel HM (for the Consensus Panel for the Diagnosis and Management of Primary Antibody Deficiencies). Consensus on diagnosis and management of primary antibody sus on diagnosis and management
deficiencies. $B M F$ 1994;308:581-5.

18 Pincus T, Callahan LF. Taking mortality in RA seriously: predictive markers, socioeconomic status and copredictive markers, socioeconomic
morbidity. $\mathcal{F}$ Rheumatol 1986;13:841-8.

19 Mitchell DM, Spitz PM, Young DY, Block DA, McShane DJ, Fries JF. Survival, prognosis and causes of death in RA. Arthritis Rheum 1986;29:706-14.

20 Shadick NA, Fanta CH, Weinblatt ME, O'Donnell W, Coblyn JS. Bronchiectasis: a late feature of severe rheumatoid arthritis. Medicine (Baltimore) 1994;73:161-70. 